\title{
Las prácticas de violencia sexual en la Salta profunda y los regímenes de (in)visibilidad mediática
}

The practices of sexual violence in the in the deeper Salta and the regimes of (in)visibility in the media

\author{
Inés Patricia Zurita zuritainesp@gmail.com \\ https://orcid.org/0000-0003-1481-0138 \\ Universidad Nacional de Salta (Argentina)
}

\section{Resumen}

El presente artículo indaga los modos de visibilidad que adquirió la violencia sexual dentro del discurso periodístico a inicios de 2019 en la provincia de Salta, teniendo en cuenta las huellas de las condiciones de producción de la información que estuvieron atravesadas a nivel local por la declaración de Emergencia Pública en materia de Violencia de Género (Decreto Nro. 7863) debido a que la provincia encabeza uno de índices de femicidios y violaciones más elevados 
del país por cantidad de habitantes. Mientras que a nivel nacional, hubo una ascendente visibilización de la violencia sexual en la agenda pública en el marco del debate por la aprobación de la Ley de Interrupción Voluntaria del Embarazo, y de las luchas emprendidas por el movimiento de mujeres y feminista que van trazando nuevos parámetros de tolerabilidad social respecto a los diversos tipos y modalidades de la violencia contra las mujeres.

El análisis se centra en las representaciones de un caso de violación en banda contra una adolescente, ocurrido en la localidad de Las Lajitas, que se textualizan en cuatro diarios digitales: El Tribuno de Salta, Nuevo Diario de Salta, Informate Salta y Qué Pasa Salta.

Palabras clave: Violencia sexual; violencia de género; representaciones sociales; prensa.

\section{Abstract}

This article studies the ways in which sexual violence is made visible in the journalistic discourse at the beginning of the year 2019 in the province of Salta, considering the traces of the conditions of production of the information that was signed at the local level by the declaration of Emergency Public on Gender Violence (Decree Nro. 7863) because it leads the highest rates of femicide and rape in the country by number of inhabitants; while at the national level, there was an ascending visibility of sexual violence on the public agenda in the debate for the approval of the Law on Voluntary Interruption of Pregnancy, and the struggles of the women's and feminist movement that are installing new parameters of tolerability with regarding the different types and modalities of violence against women.

The analysis focuses on the representations of a case of gang rape against a teenager, in the city of Las Lajitas, which is textualized in four digital newspapers: El Tribuno de Salta, Nuevo Diario de Salta, Informate Salta and Qué Pasa Salta.

Keywords: Sexual violence; gender violence; social representations; press.

El presente artículo (1) pretende ser un aporte al campo del estudio de los medios de comunicación de las zonas periféricas alejadas del centro del país, particularmente en el contexto local de Salta. Esto resulta importante porque el espacio de mediático es uno de los 'campos de interlocución' (Grimson, 2001) (2) donde se reafirma y se disputa el poder de la representación lo cual permite construir y configurar visibilidades sobre la realidad, estabilizando ciertos sentidos sociales sobre el mundo y su funcionamiento (Reguillo, 2007). 
El objetivo consistió en indagar cómo los principales diarios de circulación digital de la provincia configuraron diversas representaciones sobre la violencia sexual contra las mujeres a inicios de 2019, teniendo en cuenta las particularidades de las condiciones de producción de la información (Verón, 1989) que estuvieron signadas a nivel local por la declaración de Emergencia Pública en materia de Violencia de Género (Ley provincial Nro. 7863) ante los elevados índices de femicidios y violaciones que presenta Salta, siendo una de las provincias con la mayor cantidad de casos del país por cantidad de habitantes; mientras que a nivel nacional, durante 2018, hubo una ascendente visibilización de la violencia sexual en la agenda pública de Argentina, entre otros temas, en el marco del debate por la aprobación de la Ley de Interrupción Voluntaria del Embarazo y de la conmocionante denuncia mediática y judicial por violación que realizó la actriz Thelma Fardín contra el actor Juan Darthés, hecho ocurrido durante una gira teatral cuando ella era menor de edad.

Si bien la violencia contra las mujeres (en adelante, VCM) en general, y la violencia sexual específicamente, han sido históricamente normalizadas e invisibilizadas en la sociedad, se evidencia un fuerte cambio en los parámetros de tolerabilidad social (Arancibia y Cebrelli, 2015) es decir, la disputa cultural de lo que es aceptable y condenable socialmente, a partir de los avances e interpelaciones que vienen realizando los movimientos feministas y de mujeres que impactan en diversos ámbitos, incluyendo a las rutinas periodísticas y sus regímenes de visibilidad (Reguillo, 2007). Es por ello que, en el contexto específico mencionado, el corpus estuvo compuesto por la selección de noticias de un caso notable (Ford, 2001) de violación en banda ocurrido el 1 de enero de 2019 en la localidad de Las Lajitas, que se destacó por la trascendencia en los medios televisivos y gráficos de circulación local y nacional y cuya cobertura se realizó paralelamente a otro caso de violación en banda ocurrido el mismo día, durante la celebración de Año Nuevo, en Miramar, provincia de Buenos Aires.

Violencia sexual: inserción en la lógica simbólica del poder

Las sociedades latinoamericanas son herederas de un patrón de poder de dominación, explotación y aniquilamiento (Dussel, 2005) instalado durante la administración del colonialismo europeo en América que encuentra nuevas formas de persistir en el presente a través de significaciones que se adaptan y se modifican (Quijano, 2011). Este orden devenido en el sistema-mundo moderno, capitalista y patriarcal (Grosfoguel, 2006) se sostiene, material y simbólicamente sobre la base de la construcción de la diferencia mediante la formación de 
estructuras heterárquicas (jerarquías globales múltiples y heterogéneas) de desigualdades sexuales, de género, de clase, políticas, económicas, espirituales, lingüísticas y raciales (Ídem). La diferencia por género, en particular, aparece desde el momento del nacimiento cuando los seres humanos son clasificados y nombrados de acuerdo a su papel en la reproducción sexual de su anatomía de manera binaria (hombre/mujer), lo cual se traduce en una adscripción identitaria a grupos bio-socio-psico-culturales genéricos (Lagarde, 1996) y en una 'performatividad' (Butler, 1990) a través de un espacio-cuerpo acorde a roles, creencias, valores, costumbres, normas, deberes y prohibiciones sociales, que colocan a las identidades femeninas en una situación de inferioridad respecto a las identidades masculinas.

Este orden en las relaciones de género habilita mecanismos de dominación, opresión y violencia sobre todo contra las mujeres, que Rita Segato (2003) entiende como un esfuerzo por la restauración constante de una 'economía simbólica del poder' organizada mediante un sistema de status y un sistema de contrato. Esto convierte a las mujeres y sus cuerpos, entendidos como espacio territorial simbólico (3), en víctimas de la 'colonialidad del ser' (Maldonado Torres, 2007). Es decir, que en ellas recae una normalización de las amenazas cotidianas, que devienen de la violación del sentido de la alteridad humana hasta el punto donde el alter-ego queda transformado en un sub-alter, un ser condenado a no estar ahí, a no ser (lbídem).

La violencia sexual en contexto de guerra es el paradigma de la analogía entre cuerpo femenino y territorio colonizado porque allí la "inseminación y predación de los cuerpos de las mujeres del grupo derrotado ocurre porque ese espacio se convierte en un lugar privilegiado para significar el dominio, la potencia cohesiva masculina como índice de unión y fuerza de toda una colectividad" (Segato, 2006: 5-6). Por su parte, la violencia sexual cotidiana y actual en Latinoamérica puede ser entendida como una herencia de la no-ética europea de la guerra que consistía en violar a las mujeres del territorio enemigo hasta que finalizara la batalla- que con la conquista de América fue extendida, llevada al extremo de la naturalización, hasta el punto de producir una realidad definida por la condena perpetua de los grupos colonizados (Maldonado Torres, 2007) justificada en relación a la constitución biológica de la raza y el sexo/género.

La VCM, en este sentido, debe ser entendida por su dimensión expresiva y simbólica, más que por su dimensión instrumental (Segato, 2003). La violencia sexual, en particular, se ha ido cargando de diferentes sentidos y denominaciones a lo largo del tiempo, pasando de ser considerada por el sistema jurídico como un "delito contra la honestidad" en el orden moral a un "delito contra la integridad sexual" que atenta contra los Derechos Humanos fundamentales y que se encuentra arraigado en un orden sociocultural amplio, que utiliza esta práctica como 
canal de comunicación en dos sentidos: hacia otras mujeres, como una forma de disciplinamiento, y hacia otros hombres, como un acto de exhibición de la potencia y el dominio de la voluntad femenina dentro del proceso de producción de la masculinidad entre cofrades (ibídem).

En Argentina desde 2009 rige la Ley nacional 26485 de Protección Integral para Prevenir, Sancionar y Erradicar la VCM, la cual define a la violencia sexual como "cualquier acción que implique la vulneración en todas sus formas, con o sin acceso genital, del derecho a la mujer de decidir voluntariamente acerca de su vida sexual o reproductiva a través de amenazas, coerción, uso de la fuerza o intimidación, incluyendo la violación dentro del matrimonio o de otras relaciones vinculares o de parentesco, exista o no convivencia, así como la prostitución forzada" (artículo 5, inciso 3).

Según las estadísticas oficiales del Ministerio de Seguridad de la Nación provenientes del Sistema Nacional de Información Criminal, entre 2014 y 2017 se han registrado un total de 14.736 casos de violación y 47.316 casos de otros delitos contra la integridad sexual. El informe realizado por el programa "Las víctimas contra las violencias" ${ }_{2}$ coordinado por la Dra. Eva Giberti, da cuenta que durante 2017 se recibieron 2.439 casos de abuso sexual, donde el $70 \%$ de las personas agredidas fueron menores de edad, de estas el $68 \%$ eran niñas, el $94,8 \%$ de los agresores eran varones y el $65 \%$ fueron hombres cercanos al ámbito familiar. Estas cifras permitieron dimensionar los altos índices de ocurrencia de esta práctica, y que las principales personas agredidas son las mujeres, adolescentes, y niñas.

\section{Salta: poderío criollo y subalternidad femenina}

El análisis propuesto estuvo anclado en la provincia de Salta, territorio ubicado en el Noroeste argentino donde sus fronteras geopolíticas limitan con los países de Chile, Bolivia y Paraguay, y sus fronteras internas encuentran una diversidad de culturas que co-habitan (criolla, urbana, campesina, etnias originarias, y migrantes extranjeros) e interactúan a través del diálogo y disputa (Cebrelli, 2017; Álvarez Leguizamón, 2010). En este espacio el patrón de poder de la modernidad/colonialidad (Quijano, 2011) se erige sobre una fuerte impronta tradicionalista y criolla sostenida en la hegemonía terrateniente y de la religión católica, cuya histórica construcción de alteridades se actualiza constantemente con discursos y prácticas de marcado corte patriarcal, sexista, xenófobo, clasista y sobre todo racista (Cebrelli y Arancibia, 2011). La idea de 'raza' resulta central en la colonialidad, ya que la misma crea, desde una perspectiva biologicista, identidades "naturalmente" inferiores respecto a lo europeo o lo criollo, 
lo cual implica formas múltiples de sub-alterización y de deshumanización (Maldonado Torres, 2007). Esto es lo que sucede con las numerosas comunidades indígenas que actualmente habitan en el territorio salteño, que en el presente están sumidas en la extrema pobreza, la exclusión, la marginalidad (Ídem) y negligencia del Estado. Las comunidades son víctimas de graves enfermedades y muertes por desnutrición, explotación laboral, desocupación, mientras paralelamente se ven amenazados por el despojo, el robo, y saqueo de sus tierras por el "extractivismo" del sistema capitalista actual que busca "limpiar" étnicamente los territorios por medio del ejercicio de la violencia para que las compañías mineras, sojeras, entre otras, tomen posesión de los recursos de la tierra (Grosfoguel, 2006).

Las dinámicas interculturales en el territorio configuran un umbral tensivo, conflictivo y violento (Lotman, 1996) donde las agresiones se ven complejizadas cuando involucran una interseccionalidad (Crenshaw, 1995) entre varias identidades subalternas del tejido social. Un ejemplo lo constituye el ser mujer e indígena dentro de una región donde pervive el "chineo". Esta práctica instaurada por los españoles desde la conquista, consiste en un agrupamiento de jóvenes criollos que salen a buscar 'chinitas' (niñas o adolescentes de pueblos originarios) que co-habitan en sus localidades, a las que persiguen y toman sexualmente por la fuerza. Esto se considera 'una pauta cultural' tan internalizada que es vista como un "juego" juvenil (Cebrelli, 2018). El alto nivel de impunidad que gozan los hombres criollos, sumado a la vida por debajo de la línea de pobreza de las comunidades indígenas, ha posibilitado hasta hace poco tiempo el silenciamiento y la invisibilidad de estos graves delitos (Cebrelli, 2016; Corvalán, 2011).

Sin embargo, la VCM en Salta se constata con extrema frecuencia no sólo en territorio indígena sino en todos los rincones de la provincia de Salta, atravesando grupos, clases sociales y franjas etarias. Esto se refleja en las estadísticas que afirman que desde 2014 y hasta la actualidad la provincia posee uno de los índices más elevados de femicidios y violaciones del país por cantidad de habitantes. De acuerdo al Informe del Sistema Nacional de Información Criminal del Ministerio de Seguridad de la Nación, durante 2015 se registraron 367 casos de violaciones en la provincia con una tasa de 27,5 casos cada 100.000 habitantes, siendo la media nacional considerablemente inferior: 8,7. Estos índices posicionaron a Salta en el primer lugar de las estadísticas, por encima de la provincia de Misiones $(23,3)$ y de Mendoza $(18,9)$. Los casos disminuyeron levemente hacia 2016, siendo 250 los casos registrados por el mismo organismo. Aquí se debe tener en cuenta que la violencia sexual, al ser un delito que predomina en una instancia privada, no siempre es denunciado (Observatorio de Violencia contra las Mujeres, 2016) pero estos y otros datos permiten dimensionar los altos niveles de vulnerabilidad que padecen las mujeres en el territorio provincial, lo cual se ve agravado 
cuando el Estado las re-victimiza mediante el incumplimiento del derecho de acceso al aborto no punible en caso de violación (4).

Por todo esto el gobierno local se vio obligado a promulgar el Decreto Ley de Emergencia Pública en materia de Violencia de Género por dos años (Ley provincial 7863), la cual debió ser prorrogada dos años más, hasta 2018, y más recientemente hasta 2020 debido a la persistencia de las agresiones.

\section{Delimitaciones teórico-metodológicas y temporales}

La esfera mediática constituye en nuestros días uno de los espacios donde se dirimen, visibilizan y ocultan los diversos escenarios sociales y asuntos públicos (Morelli y Rey, 2011). En este sentido, a pesar de que en la provincia de Salta rige una Emergencia por Violencia de Género, pocos casos han ingresado a la agenda de los medios de comunicación. En la prensa salteña, según se pudo constatar, desde 2015 hubo un notable ingreso de noticias sobre casos de femicidios, sin embargo, esto no ocurrió con los casos que involucran otras expresiones menos extremas de la VCM, como lo es la violencia sexual que no es seguida de muerte (Zurita, 2018). Esto se vio gradualmente modificado hacia el año 2018, cuando se observó un leve aumento en la visibilización de la problemática.

Entendiendo que los medios no solo informan, sino que también son constructores de representaciones sociales, estas últimas vinculadas a la violencia sexual fueron el eje del análisis. Las mismas son entendidas como una articulación entre las prácticas y los discursos, son mecanismos traductores que tienen "una facilidad para archivar y hacer circular con fluidez conceptos complejos cuya acentuación remite a un sistema de valores, roles, modos de hacer y de ser, y modelos de mundo de carácter cultural, ideológico e histórico" (Cebrelli y Arancibia, 2005: 38). En este punto es importante destacar que las representaciones que se textualizan en los medios de comunicación se vuelven complejas porque dentro de los mismos tienen un fuerte impacto en los procesos de circulación y validación sobre las prácticas sociales (Cebrelli y Rodríguez, 2013) instalando un efecto de realidad y de verdad que espectaculariza los rasgos positivos y negativos de un objeto o acontecimiento.

Debido a que la producción de conocimiento siempre se sitúa desde un lugar particular de las estructuras de poder (Grosfoguel, 2006), las características inherentes del objeto de estudio demandaron una mirada epistemológica anclada críticamente desde una perspectiva de género, atenta a las desigualdades que afectan a las identidades femeninas en tanto grupo subalterno (Lagarde, 1996). Desde esta perspectiva se realizó un análisis de corte cualitativo- 
comprensivo que recogió los aportes del análisis del discurso de base lingüística y sociosemiótica (Verón, 1987; Lotman, 1996; Filinich, 1998; Marafioti, 1997) y de las representaciones sociales (Cebrelli y Arancibia, 2015) que se construyen en el discurso de la información (Charaudeau, 2003) para inferir los 'regímenes de visibilidad hegemónica' (Reguillo, 2007) que operan en el plano de la enunciación discursiva de las noticas sobre la violencia sexual.

La conformación del corpus de análisis consistió en la selección de noticias sobre un 'caso notable' (Ford, 2001), entendido como un acontecimiento singular que quiebra la cotidianeidad y tienen algún grado de impacto social. La muestra quedó conformada por dieciséis noticias que informaron sobre la violación en banda de una adolescente de 14 años, ocurrida el 1 de enero de 2019, durante las celebraciones de Año Nuevo en la localidad de Las Lajitas. Las mismas fueron extraídas de los portales digitales locales de mayor circulación en la web: El Tribuno de Salta, Nuevo Diario de Salta, Informate Salta y Que Pasa Salta.

\section{Contextualización del caso}

Las Lajitas es una localidad de 7.688 habitantes que se ubica en el departamento de Anta, a 230 kilómetros al este de la ciudad capital de Salta, y se caracteriza por concentrar el $65 \%$ de la producción provincial del cultivo de soja para la exportación. Allí el 1 de enero de 2019, durante la madrugada del año nuevo, una menor de 14 años fue violada por varios hombres mayores de edad y rescatada por su madre. Luego de cenar y brindar con su familia, la adolescente se acercó a hablar con una amiga a pocas cuadras de su domicilio. A las cuatro de la mañana, como no volvía, su madre salió a buscarla y una vecina le advirtió que la habían obligado a entrar a la fuerza a otra vivienda. La mujer se dirigió a la dirección indicada pero la dueña de la propiedad, madre de uno de los agresores, la atendió y negó que su hija estuviera ahí. Ante los gritos de auxilio, irrumpió por la fuerza a la habitación donde estaba cautiva por un grupo de varones. Durante los días siguientes el pueblo entero se movilizó por las calles en pedido de justicia.

Esa madrugada estuvo signada por numerosos abusos sexuales en distintos puntos del país, por lo cual la elección del caso no fue caprichosa. Un hecho similar ocurrió simultáneamente en la ciudad costera de Miramar ubicada en la provincia de Buenos Aires, donde en un camping, cinco hombres violaron a una menor de 14 años. Este caso marcó la agenda de los medios de circulación nacional e impulsó la visibilización del caso de Las Lajitas. Sin embargo, la cobertura periodística se alejó de una correcta comprensión de lo sucedido, culpabilizando a la 
adolescente y a su familia de la violencia que padeció. Un ejemplo pudo leerse en las páginas del diario Clarín, uno de los medios con mayor impacto y alcance en el país, que sostuvieron que la "chica de 14 años no debió estar allí, sino con sus padres y su hermano festejando el Año Nuevo, en otra carpa".

Por otro lado, el 11 de diciembre de 2018, semanas antes del caso notable (Ford, 2001) seleccionado, una denuncia judicial de violencia sexual se instaló en primer orden de importancia de las agendas mediáticas del país porque involucró a varias figuras públicas. Sobre el escenario de un teatro, la actriz argentina Thelma Fardín, de 26 años, acompañada de la colectiva Actrices Argentinas, brindó una conferencia de prensa en la que narró en detalle la violación que padeció en 2009, cuando tenía 16 años, por parte del actor Juan Darhés, que en ese entonces tenía 45 años, en el contexto de la gira de una obra teatral infantil en Nicaragua. La visibilización de la denuncia rápidamente fue viralizada por las redes sociales, instalándose la consigna "mirá cómo nos ponemos" que impulsó a miles de mujeres a reconocer, poner en palabras y denunciar las experiencias vividas que involucraron acoso, violación y abuso sexual. Un hecho similar había sucedido dos años atrás con la consigna "no nos callamos más" que estuvo vinculada a numerosas denuncias de violencia de género contra integrantes de bandas de rock, la cual encontró un paralelismo con el movimiento "me too" en Estados Unidos.

Estas expresiones fueron dejando en evidencia el entramado de poder que amenaza y vulnera la vida y la integridad sexual de niñas, adolescentes y mujeres en los diversos ámbitos donde se desarrollan. Las mismas son herederas de las décadas de luchas y manifestaciones de los grupos de mujeres y feministas que vienen emergiendo desde los márgenes o las grietas (Walsh, 2015) de un sistema patriarcal, y que van modificando gradualmente los 'regímenes de (in)visibilidad', entendidos como un "conjunto de tácticas y estrategias que, de manera cotidiana, gestionan la mirada, esa que produce efectos sobre el modo en que percibimos y somos percibidos" (Reguillo, 2007: 2).

\section{Una aproximación a los procesos de significación de la violencia sexual}

Las noticias publicadas entre los días 2 y 11 de enero de 2019 que informaron sobre la violación en banda ocurrida en Las Lajitas fueron configurando representaciones a partir de determinados procedimientos lingüísticos y discursivos que pusieron de manifiesto los procesos de producción de sentido. Fue por ello que se analizaron los campos semánticos, es decir, los lexemas y/o sintagmas (Courtes, 1980) cuyos significados presentaban algún sema 
común, permitiendo dar cuenta de una cadena equivalencial de significación anclada en las condiciones de producción sociales e históricas (Verón, 1986).

El discurso periodístico se caracteriza por mantener una relación estrecha entre información, verificación, legitimidad y calidad (Cebrelli, 2012) que se traduce en el uso de fuentes informativas y en el intento de borrar todas las huellas del enunciador. Por ello, las fuentes oficiales de la policía y del poder judicial ocuparon un protagonismo privilegiado en las piezas analizadas, ya que las mismas tienen un importante poder dentro de las instituciones del Estado y otorgan un fuerte 'efecto de verosimilitud' a los datos proporcionados (Martini, 2000). El enfoque de las noticias, en consecuencia, se construyeron a partir de la mirada de dichas fuentes, que construyeron el hecho como un crimen aislado y excepcional, obviando su dimensión sociocultural e histórica. A su vez, las instituciones policiales y judiciales, haciendo uso de su capacidad privilegiada para tomar la palabra y ejercer el poder de la (auto) representación (Reguillo, 2007), crearon imágenes positivas de sí para legitimar sus prácticas, que se anclaron en un imaginario cargado de ideas de eficacia, rapidez y formación profesional de sus trabajadores ante situaciones que atentan contra la vida y la integridad de las personas, las cuales no se sustentaron sobre saberes de conocimiento empírico y validado, sino en saberes de creencia (Charaudeau, 2003).

La representación positiva de las instituciones oficiales, sin embargo, fueron rápidamente refutadas a medida que ingresaron como fuentes testimoniales las voces de los familiares de la adolescente agredida, quienes en sus declaraciones expusieron las falencias en los mecanismos estatales a la hora de prevenir la VCM, tanto por las tramas de impunidad que envuelven a los casos de la violencia sexual en el ámbito policial y judicial, como por la negligencia que padecen por parte de las instituciones médicas:

\begin{abstract}
Pedimos justicia, que estos tipos no entren y salgan por la puerta porque desgraciadamente eso es lo que está pasando, y hoy es ella, pero hay muchas nenas violadas', precisó la tía de la víctima. Además, denunció que le dieron el alta sin haber aplicado el kit profiláctico (El Tribuno de Salta, 2/01/2019).
\end{abstract}

\begin{abstract}
Mientras tanto, la comunidad de Las Lajitas se movilizó ayer por las calles céntricas del pueblo para visibilizar la problemática. 'No queremos que lo que le pasó a mi sobrina quede impune. Ha habido otros casos y los violadores siguen paseando por acá como si nada (...)', sentenció Mónica (Que Pasa Salta, 8/01/2019).
\end{abstract}

Por otro lado, el territorio de las Las Lajitas estuvo representado como un espacio pacífico, sin violencia, como un "apacible pueblo del departamento Anta" (El Tribuno de Salta, 8/01/2019) 
que toleraba mansamente los abusos sexuales, pero que ahora entendió que es un delito por el cual tiene derecho a exigir justicia. Así, la comunidad se vio obligada a participar activamente en los lugares de visibilidad y decibilidad públicos y mediáticos, mediante numerosas manifestaciones y escraches que generaron un clima de tensión tras la conmoción, indignación y rechazo generalizado de lo sucedido sumado a la falta de credibilidad en las instituciones que deben garantizar su pedido de justicia. Esta construcción puede atribuirse a la coyuntura social antes descripta, que con el lema "no nos callamos más" o "mirá como nos ponemos" animó a la sociedad a levantar la voz y promover acciones ante las injusticias que afectan a las mujeres, creando con una ruptura con la histórica normalización y silenciamiento de la VCM.

En la mayoría de las noticias analizadas, para nombrar a la violencia sexual, se emplearon los lexemas "abuso sexual" y "violación" como cadena equivalencial de significación. La mención directa resulta positiva ya que como señalan otras investigaciones durante muchos años estos casos fueron invisibilizados o visibilizados mediante estrategias discursivas inadecuadas a partir del uso de eufemismos que ocultaban, negaban o atenuaban su gravedad (Alochis, 2016). Estos lexemas, sin embargo, fueron acompañados por una abundante utilización de metáforas vinculadas a la tragedia, el drama y el miedo que sirvieron para banalizar y espectacularizar la narración de lo sucedido como por ejemplo: "(...) horrendo caso ocurrido en Año Nuevo" (El Tribuno de Salta, 8/01/2019); "la víctima del abuso sexual en banda continúa shockeada por el terrible drama que sufrió" (El Tribuno de Salta, 8/01/2019); "una pesadilla en Año Nuevo" (Que Pasa Salta, 4/01/2019); "horror en Las Lajitas" (Informate Salta, 3/01/2019).

A fin de satisfacer las demandas mercantiles de las empresas periodísticas, muchos de estos lexemas fueron incluso jerarquizados dentro de los titulares, es decir, en los elementos de mayor importancia de las noticias, porque son los que producen el enganche del lector (Peralta y Urtasun, 2007) a partir de sintagmas que producen sensaciones y despiertan curiosidad (Barcaglione, 2010). Hacia el cuerpo de la noticia, el abordaje recayó en la exhibición y descripción de detalles escabrosos e impactantes sobre la manera en que la adolescente fue agredida:

La víctima fue asistida en el hospital local donde se determinó que presentaba desgarramiento en sus partes íntimas, mordeduras y moretones en distintas partes del cuerpo, además de signos evidentes de que estaba alcoholizada y drogada (El Tribuno de Salta, 8/01/2019).

De este modo, colocando el foco en la escritura cruenta de la violencia, la información se convirtió en un producto rentable y de consumo masivo, mientras exhibió la potencia del poder 
masculino, asegurando su reproducción y circulación social a gran velocidad. Rita Segato (2013) supone la existencia de una 'pedagogía de la crueldad' (5), la cual se ejerce desde el Estado, desde la estructura social y desde los medios de comunicación, que acostumbra a los y las ciudadanas y al público al espectáculo de la crueldad, lo cual atenta contra la empatía, la sensibilidad y genera un efecto de anesteciamiento (Cebrelli y Arancibia, 2015) en el imaginario social que recae en un nuevo ocultamiento y una nueva cuota de naturalización del problema de la VCM (Didi-Huberman, 2014). Asimismo, se ejercen nuevas formas de VCM, de tipo simbólica y de modalidad mediática, entendida como "la que, a través de patrones estereotipados, mensajes, valores, íconos o signos transmita y reproduzca dominación, desigualdad y discriminación en las relaciones sociales, naturalizando la subordinación de la mujer en la sociedad" (Ley 26485, artículo 5, inciso 5).

Este abordaje reafirmó la representación de la violencia sexual como un acontecimiento circunstancial, excepcional o aislado, lo cual se complementó con la ausencia de cifras y datos duros, sustentados en saberes de conocimiento (Charaudeau, 2003) que permitan dimensionar la problemática o contextualizarla en relación a otros casos, tal como se pudo constatar con el ingreso de las cifras de femicidios registrados a nivel a regional en una gran cantidad de noticias de esta índole (Zurita, 2018).

En lo que respecta a la construcción del género en torno a la violencia sexual, la identidad femenina, en primer lugar, fue identificada a través de diversos apelativos delocutivos, es decir términos que "se utilizan para referirse al sujeto de quien se habla desde un rol o estatus social" (Marafioti, 1997: 138) que resaltaron, por un lado, la franja etaria a la que perteneció como: la niña, la chica, la jovencita, la menor, la adolescente; y por otro lado, su rol de víctima: "la víctima emborrachada, drogada y abusada sexualmente en banda" (El Tribuno de Salta, 2/01/2019); "una niña haya sido ultrajada y vejada" (El Tribuno de Salta, 8/01/2019); "la víctima abusada" (El Tribuno de Salta, 8/01/2019).

El lexema víctima y su opuesto, victimario, provienen del léxico empleado por el discurso jurídico, el cual tiene una larga data en la historia de la cultura y se encuentra rígidamente impregnado de sentidos ideológicos patriarcales que se transmiten al discurso periodístico como fuente oficial de información (Alochis, 2016). En este sentido, dentro de las relaciones de género, la violencia sexual, sea perpetrada de manera individual o colectivamente por un grupo de varones, implica una dimensión expresiva en tanto un acto moralizador de reducción del territorio-cuerpo y supresión de la voluntad femenina que es equivalente, en términos de economía simbólica patriarcal, al asesinato (Segato, 2003). Acorde a esto, la representación de víctima se cargó de sentidos que instalaron al hecho de violación como una herida fatal, muerte 
simbólica o una marca altamente traumática para la salud psíquica de la mujer que puede resultar insuperable o de lo que jamás podrá escapar (Alochis, 2016):

La menor abusada permanece internada aún en estado de shock en el hospital de Las Lajitas. Según los familiares la menor de 14 años no pudo superar el terrible drama por el abuso sexual en banda que sufrió (El Tribuno de Salta, 8/01/2019).

La imagen de víctima remitió, además, a la idea de silencio, inacción en tanto pasividad y sumisión que responde a los atributos propios de la feminidad hegemónica dentro de un sistema sexo/genérico binario (Tufró, Ruiz y Huberman, 2012), todo lo cual ocultó u opacó de la representación la capacidad de resiliencia, de acción, de lucha o empoderamiento que tienen numerosas mujeres para asegurarse una vida plena y digna, a pesar de haber padecido hechos de la violencia en el pasado: "(...) solo emite algunas palabras con su madre, sin hacer referencia a lo ocurrido esa madrugada" (Nuevo Diario de Salta, 9/01/2019).

Como se observa en el fragmento, la narración de las noticias por momentos y en un intento de correr el eje de culpabilidad hacia la persona agredida, enfatizó en las altas horas de la madrugada en la que una adolescente circulaba por el espacio público. Esto responde a un espesor temporal que data del siglo XVIII hasta mediados del siglo XX, cuando la división sexual del trabajo o la prohibición de tareas según el sexo (Lévi-Strauss, 1976) estableció, connotando atribuciones de lo masculino y de lo femenino, que el espacio público fuera territorio meramente masculino (incluyendo el Estado y sus instituciones, el ámbito político y del mercado) mientras la privacidad del mundo del hogar y la familia se construía como el espacio propio de lo femenino en donde brindaran atención las y los niños, hombres y adultos mayores (Fernández, 1993). En consecuencia, el discurso informativo configuró al cuerpo femenino en el espacio público en un horario determinado, como una acción de desacato a la norma patriarcal. Esto se vio agravado por el hecho de que la mujer era menor de edad porque aumentó su grado de vulnerabilidad, lo que permitió correr la responsabilidad sobre los agresores hacia la madre, quien fue objeto de numerosos cuestionamientos: "La mujer siente culpa y malestar al leer comentarios donde se la acusa de ser una mala madre" (Informate Salta, 11/01/2019). Estas retóricas mediáticas dieron cuenta de una dimensión pedagógica de la violencia sexual, en tanto implican procesos de formación de subjetividades (Cremona y Ficoseco, 2015: 6), que advertirían de las consecuencias punitivas que tienen ciertas acciones femeninas que se corren de una posición de sumisión al orden patriarcal (Segato, 2003). De manera opuesta y complementaria, los agresores que perpetraron la violación grupal fueron identificados a partir de sus nombres propios y edades, resaltando la condición de personas 
adultas, mayores de edad, con capacidad de responder sobre sus actos ante la ley. Asimismo, fueron mencionados a partir de los apelativos delocutivos (Marafioti, 1997) que dieron cuenta de su rol de autores o sospechosos de ejercer un acto ilícito a partir de los lexemas: "los detenidos", "los acusados".

La representación, de este modo, se construyó alrededor de una imagen negativa vinculada la criminalidad y la violencia. Estos aspectos respondieron, aunque de manera abyecta, a los mandatos que establece la subjetividad de la masculinidad hegemónica, entendida como una construcción cultural, histórica y patriarcal que define un modo de ser varón a partir de roles que despliegan autoridad, poder y dominación sobre las mujeres y también sobre otras identidades masculinas (Kaufman, 1990).

La violencia se presenta como un recurso indispensable de este mandato ya que es una manera de exigirla o afirmarla tanto en las luchas entre pares como en la violencia física o sexual contra las mujeres (Connell, 1997). Esto último es necesario porque la masculinidad hegemónica, en tanto exigencia social inalcanzable, siempre se encuentra bajo sospecha y debe ser revalidada y comprobada ante los ojos de otros hombres (Gilmore, 1990) alejándose de cualquier rasgo feminizado asociado a las mujeres, pero también a las personas homosexuales, trans, niños y niñas (Kimmel, 1997).

A pesar de que las exigencias violentas del mandato de masculinidad se despliegan en la cotidianeidad, atravesando diversas clases sociales, etnias y franjas etarias, los enunciadores presentaron a los agresores como hombres "depravados", "degenerados" y "malvivientes", es decir, como desviados de las normas sociales o amorales, tal como pudo leerse en el siguiente párrafo: "EI hecho de saber que estos degenerados están ahí, detrás de esas paredes, agiganta nuestra bronca', dijo Paulina, tía de la víctima" (El Tribuno de Salta, 8/01/2019). El término "depravados", fue un lexema recurrente al igual que "degenerados" y "malvivientes": "Los malvivientes se vistieron rápidamente y escaparon" (Informate Salta, 03/01/2019).

Los 'regímenes de visibilidad' (Reguillo, 2007), de esta manera, construyeron una imagen de los violadores desde una lógica patologizante que los ubicó en el lugar de un 'otro', anómalo o enfermo, que no es consciente de la responsabilidad y las consecuencias de sus actos, alejado del comportamiento del lector modelo de los diarios. Todo esto fue reforzando la persistencia de representaciones sobre la violencia sexual contra mujeres como hechos aislados y desanclado de su contexto histórico y social.

\section{Reflexiones}


El análisis realizado permitió ver las dinámicas presentes en la construcción de representaciones sobre la violencia sexual en el discurso de la información. Por un lado, se instalaron una serie de sentidos sobre el hecho, los agresores y la mujer agredida, provenientes del sistema ideológico patriarcal, entramado en los tiempos largos y medios de la memoria colectiva. Estas representaciones reforzaron ciertos prejuicios y estereotipos de género, y construyeron al caso como un hecho aislado y circunstancial desde el marco interpretativo policial y judicial. A su vez, mediante la exposición de los detalles escabrosos y dramáticos de la violación, la información fue colocada en función de las lógicas mercantiles de las empresas periodísticas, a costa del ejercicio de la violencia mediática.

Por otro lado, aunque en menor medida, las noticias también estuvieron permeadas por los significados provenientes de fenómenos sociales emergentes en el contexto de la producción de la información, los cuales resistieron, negociaron y cuestionaron los saberes patriarcales arraigados. Estos elementos se hicieron visibles mediante las voces de las fuentes testimoniales de los familiares de la adolescente agredida y los miembros de la comunidad de Las Lajitas, sin embargo, no fueron suficientes para establecer representaciones "otras" sobre la violencia sexual contra mujeres, niñas y adolescentes que problematicen el hecho desde un enfoque con perspectiva de género y de derechos humanos, lo cual resulta fundamental en un contexto de emergencia como el que se vive en Salta.

\section{Notas}

(1) El presente artículo se inscribe dentro del proyecto de investigación: CIUNSa Nro. 2307/0, "La construcción de la diferencia y la desigualdad en la producción mediática e hipermediática local. Las narrativas informativas y ficcionales en el período 2009-2015" dirigido por la Dra. Alejandra Cebrelli.

(2) Alejandro Grimson (2001) sostiene que los campos de interlocución son un marco dentro del cual ciertos modos de identificación son posibles mientras otros quedan excluidos; donde determinados grupos se posicionan a partir de diálogos y conflictos.

(3) Existen afinidades semánticas entre el cuerpo y el territorio, debido a que el cuerpo es habitado como un espacio de soberanía, y es el primero y último bastión de la identidad (Segato, 2006). El cuerpo, así entendido, no se reduce a un simple funcionamiento fisiológico, debido a que excede cualquier noción de maquinaria biológica al encontrarse atravesado por funciones sociales, culturales, económicas y políticas que fueron situadas históricamente y que a menudo son móviles y negociables (Lamas, 2000).

(4) Desde 1921, el Código Penal Argentino permite el aborto en dos supuestos: cuando está en peligro la vida o la salud de la mujer y cuando el embarazo es producto de una violación (artículo 86, inciso 1-2) sin requerirse autorización judicial previa para acceder a la práctica y sin que exista obligación de realizar la denuncia penal del delito. El gobernador de Salta, Juan Manuel Urtubey, adhirió al protocolo que garantiza el acceso al aborto no punible (ANP) recién a fines de 2017 .

Question, Vol. 1, N. ${ }^{\circ}$ 63, julio-septiembre 2019. ISSN 1669-6581

Instituto de Investigaciones en Comunicación | Facultad de Periodismo y Comunicación Social | Universidad Nacional de La Plata La Plata | Buenos Aires | Argentina

Página 15 de 18 
(5) El desarrollo del concepto y las citas de este párrafo fueron extraídas de la siguiente entrevista: http://perio.unlp.edu.ar/node/4602

\section{Bibliografía}

Álvarez Leguizamón, S. (2010). Introducción. En Poder y Salteñidad. Saberes, políticas y representaciones sociales. Salta: CEPHIA, Facultad de Humanidades.

Alochis, I. M. (2016). Representaciones sobre la violencia sexual contra las mujeres y niñas en la prensa gráfica de Córdoba. Análisis lingüístico textual de las noticias (1983-2013). (Tesis Doctoral). Centro de Estudios Avanzados, Universidad Nacional de Córdoba.

Atorressi, A. (1996). Los estudios semióticos. El caso de la crónica periodística. Buenos Aires: Pro-Ciencia-CONICET.

Barcaglione, G. (2010). Los femicidios en los medios de comunicación. En Santoro, S. y Chaher, S. (comp.). Las palabras tienen sexo II: herramientas para un periodismo de género (pp. 143-162). Buenos Aires: Artemisa Comunicación Ediciones.

Butler, J. (1990). El género en disputa. Buenos Aires: Paidós.

Cebrelli, A. (2017). Escrituras, cuerpos femeninos y medios. El $8 \mathrm{M}$ en Argentina. Improntas de la Historia y la Comunicación, 5. Recuperado de https://doi.org/10.24215/24690457e020

Cebrelli, A. (2018). Que me escuche, que me entienda, que me salve. Atravesando cuerpos y silencios. En Ares, P. (comp). Mujeres que transforman, experiencias que inspiran. Buenos Aires: Editorial Vi-Da Global, Fundación Contemporánea.

Cebrelli, A. (2019). El chineo es muy difícil de erradicar porque se transformó en una costumbre. Voces Críticas, febrero. Recuperado de https://bit.ly/2IDuQmo

Cebrelli, A. y Arancibia, V. (2015). Sobre y sub-exposición de los otros. Representaciones nodales y construcción de visibilidades. VIII Seminario Regional Cono Sur ALAIC, Córdoba.

Cebrelli, A. y Rodríguez, M. G. (2013). ¿Puede invisibilizarse el subalterno? Algunas reflexiones sobre representaciones y medios. Tram(p)as de la comunicación y la cultura, 76, julio-octubre, UNLP.

Charaudeau, P. (2003). El discurso de la información. La construcción del espejo social. Barcelona: Gedisa. 
Connell, R. (1997). La organización social de la masculinidad. En Valdéz, T. y Olavarría, J. (eds.). Masculinidad/es. Poder y crisis (pp. 31-48). Santiago de Chile: Ediciones de las Mujeres.

Corvalán, E. (2011). La costumbre de violar niñas wichi. Revista Reflexiones Marginales. Revista de saberes de frontera, 10.

Cremona, F. y Ficoseco, V. (2015). Showmatch. La espectacularización de la masculinidad en un mundo de paradigmas en crisis. Revista Question, 1(57), Universidad Nacional de La Plata.

Crenshaw, K. (1995). Critical Race Theory: The Key Writings that Formed the Movement. Nueva York: The New York Press.

Didi-Huberman, G. (2014). Pueblos expuestos, pueblos fulgurantes. Buenos Aires: Manantial.

Dussel, E. (2005). Transmodernidad e interculturalidad (Interpretación desde la Filosofía de la Liberación). En Filosofía de la Cultura y Transmodernidad. México: UACM.

Fernández, A. M. (1993). La mujer de la ilusión. Buenos Aires: Paidós.

Filinich, M. I. (1998). Enunciación. Buenos Aires: EUDEBA.

Ford, A. (2001). La marca de la bestia. Identificación, desigualdades e infoentretenimiento en la sociedad contemporánea. Buenos Aires: Norma.

Gilmore, D. (1990). Manhood in the making. Cultural concepts of masculinity. New haven: Yale University Press.

Grimson, A. (2001). Dimensiones de la comunicación. En Interculturalidad y Comunicación (pp. 5-94). Buenos Aires: Norma.

Grosfoguel, R. (2006). La Descolonización de la Economía Política y los Estudios Postcoloniales: Transmodernidad, pensamiento fronterizo y colonialidad global. Tabula Rasa, 4, pp. 17-48, enero-junio, Bogotá, Colombia.

Kaufman, M. (1997). Las experiencias contradictorias del poder entre los hombres. En Valdéz, T. y Olavarría, J. (eds.). Masculinidad/es. Poder y crisis. Santiago de Chile: Ediciones de las Mujeres.

Kimmel, M. (1997). Homofobia, temor, vergüenza y silencio en la identidad masculina. En Valdéz, T. y Olavarría, J. (eds.). Masculinidad/es. Poder y crisis. Santiago de Chile: Ediciones de las Mujeres.

Lagarde, M. (1996). El Género y feminismo. Desarrollo humano y democracia. Madrid: Horas y HORAS.

Lévi-Strauss, C. (1976). Polémica sobre el origen y la universalidad de la familia. Barcelona: Anagrama.

Lotman, J. (1996). La semiosfera 1. Madrid: Frónesis. 
Maldonado Torres, N. (2007). Sobre la colonialidad del ser: contribuciones al desarrollo de un concepto. En Castro Gómez, S. y Grosfoguel, R. (eds.). El giro decolonial. Reflexiones para una diversidad epistémica más allá del capitalismo global (pp. 127-167). Bogotá: lesco-Pensar-Siglo del Hombre Editores.

Marafioti, R. (1997). Recorridos semiológicos. Buenos Aires: EUDEBA.

Martini, S. (2000). Periodismo, noticia y noticiabilidad. Buenos Aires: Grupo Editorial Norma.

Morelli, M. y Rey, P. (2011). La violencia hacia las mujeres en los medios de comunicación. Hallazgos del Observatorio de Medios-2010. En Equipo Latinoamericano de Justicia y Género (ELA). Los derechos de las mujeres en la mira (pp. 19-43). Buenos Aires: Informe Anual de los Observatorios de Sentencias Judiciales y de Medios.

Observatorio de Violencia contra las Mujeres Rosana Alderete (2016). Informe Anual 2016.

Gobierno de la Provincia de Salta, Salta.

Peralta, D. y Urtasun, M. (2007). La crónica periodística. Lectura crítica y redacción. Buenos Aires: La Crujía.

Quijano, A. (2011). Colonialidad del poder y subjetividad en América Latina. En Contextualizaciones latinoamericanas, 5 .

Reguillo, R. (2007). Saber y poder de representación: la(s) disputa(s) por el espacio interpretativo. Comunicación y sociedad, 9, pp. 11-33.

Segato, R. L. (2003). Las estructuras elementales de la violencia. Buenos Aires: Prometeo.

Trufó, L.; Ruiz, L. y Huberman, H. (2012). Modelo para armar: nuevos desafíos de las masculinidades juveniles. Buenos Aires: Trama-Lazos para el desarrollo.

Verón, E. (1986). La Semiosis Social. Barcelona: Gedisa.

Walsh, K. (2015). Notas Pedagógicas desde las Grietas Decoloniales. Clivajes. Revista de Ciencias Sociales, 4(1).

Zurita, I. P. (2018). La representación de la mujer en la prensa gráfica salteña y su vinculación con la construcción de la violencia de género. (Tesis de Grado). Universidad Nacional de Salta. 